OPEN ACCESS

Edited by:

Roberto Pola,

Università Cattolica de/ Sacro

Cuore, Italy

Reviewed by:

Zsuzsa Bagoly,

University of Debrecen, Hungary Yung-Wei Chi,

University of California, Davis, United States

*Correspondence: Anders Gottsäter anders.gottsater@med.lu.se

Specialty section:

This article was submitted to Thrombosis,

a section of the journal

Frontiers in Cardiovascular Medicine

Received: 09 September 2021 Accepted: 07 December 2021 Published: 23 December 2021

Citation:

Gottsäter A (2021) Antithrombotic Treatment in Lower Extremity Peripheral Arterial Disease. Front. Cardiovasc. Med. 8:773214.

doi: 10.3389/fcvm.2021.773214

\section{Antithrombotic Treatment in Lower Extremity Peripheral Arterial Disease}

\author{
Anders Gottsäter* \\ Department of Internal Medicine, Skåne University Hospital, University of Lund, Malmö, Sweden
}

Lower extremity arteries might be affected by atherosclerotic peripheral arterial disease (PAD), or by embolization causing ischaemic symptoms. Patients with PAD often have widespread atherosclerosis, and progression of PAD is associated with increased risk for both other cardiovascular events and cardiovascular mortality. Peripheral arterial disease patients should therefore be offered both non-pharmacological and pharmacological secondary prevention to reduce the risk for future ischemic arterial complications. This review is focussed on the rationale for recommendations on antiplatelet and anticoagulant treatment in PAD. Asymptomatic PAD does not warrant either anticoagulant or antiplatelet treatment, whereas patients with ischaemic lower extremity symptoms such as intermittent claudication or critical limb ischemia caused by atherosclerosis should be offered platelet antiaggregation with either low dose aspirin or clopidogrel. Combined treatment with aspirin and low-dose of the direct oral anticoagulant (DOAC) rivaroxaban should be considered and weighed against bleeding risk in symptomatic PAD patients considered at high risk for recurrent ischaemic events and in patients having undergone endovascular or open surgical intervention for PAD. Patiens with cardiogenic embolization to lower extremity arteries should be recommended anticoagulant treatment with either one of the DOACs (apixaban, dabigatran, edoxaban, and rivaroxaban) or warfarin.

Keywords: atherosclerosis, antiplatelet treatment, anticoagulation, peripheral atherosclerosis, PAD

\section{INTRODUCTION, BACKGROUND}

Peripheral arterial disease (PAD) is a common atherosclerotic manifestation $(1,2)$ most often occurring in lower extremity arteries. The condition might be asymptomatic, but both focal atherosclerotic lesions in the peripheral arteries and cardiogenic embolization to the lower extremities might cause ischaemic symptoms such as intermittent claudication defined as pain induced by walking $(3,4)$, or acute or chronic limb threatening ischemia (CLTI) defined as rest pain or ulceration $(3,4)$.

Patients with atherosclerotic PAD have widespread atherosclerosis and higher rates of cardiovascular events than patients with cardio- or cerebrovascular diseae (5). As both a low ankle-brachial index (ABI) (6) and progression of PAD (7) are related to increased risk for cardiovascular events and mortality, efficient treatment of atherosclerotic risk factors is recommended in PAD patients $(3,4)$.

Thrombolytic, endovascular, and open surgical treatment in the acute or chronic stages of PAD caused by peripheral atherosclerosis or embolization are covered in current guidelines $(3,4)$ together with recommendations on smoking cessation (8), lipid (9), and blood pressure (10) 
lowering. This review is focussed upon antithrombotic treatment as secondary prevention of cardiovascular mortality and morbidity in patients with lower extremity ischemia caused by either peripheral atherosclerosis or cardiac embolization (Tables 1, 2).

\section{ANTITHROMBOTIC TREATMENT IN ASYMPTOMATIC PERIPHERAL ATHEROSCLEROTIC DISEASE}

No beneficial effects of antithrombotic treatment have been established in patients with asymptomatic PAD, i.e., a low $A B I$ without symptoms from the lower extremities or other concomitant vascular disease. In 3,350 asymptomatic subjects from the general population with $\mathrm{ABI} \leq 0.95$ detected at screening, aspirin did not confer any significant reduction in vascular events compared with placebo (11). Neither could any benefits with regard to cardiovascular events or major amputation be shown when effects of aspirin $100 \mathrm{mg}$ daily were compared to placebo in patients with asymptomatic PAD $(\mathrm{ABI} \leq$ $0.99)$ and concomitant diabetes $(12)$. Current guidelines $(3,4)$ do therefore not recommend antiplatelet treatment in PAD patients without other symptomatic manifestations of atherosclerotic disease (Table 1).

\section{ANTITHROMBOTIC TREATMENT IN SYMPTOMATIC STABLE PERIPHERAL ATHEROSCLEROTIC DISEASE}

The antiplatelet trialists'meta-analysis (13) published already in 2002 established that different types of antiplatelet therapy reduce the risk of vascular death, myocardial infarction, and stroke by approximately $25 \%$ among patients with mainly symptomatic coronary and cerebrovascular disease. Patients with different manifestations of PAD were included as a subgroup in the meta-analysis, and a $23 \%$ odds reduction for vascular events could be demonstrated in this group (13). Randomized placebo-controlled studies performed exclusively in patients with stable PAD showing benefits of low dose aspirin for reduction of symptoms or cardiovascular events are lacking, however, whereas the ADP-receptor blocker thienopyridine ticlopidine was shown to be beneficial in this regard already in 1990 in a small study of 687 patients (40). The use of ticlopidine is limited by its gastroenterological and hematological side effects, however. Another thienopyridine, clopidogrel, was therefore compared with aspirin in patients with either myocardial infarction, ischemic stroke, or PAD in the CAPRIE trial (14). In the CAPRIE subgroup of 6,452 patients with PAD, clopidogrel reduced both cardiovascular mortality [hazard ratio (HR) 0.76, 95\% confidence interval (CI) 0.64-0.91] and major cardiovascular adverse events (HR 0.78, 95\% CI 0.65-0.93) compared to aspirin (14). When clopidogrel was later compared with ticagrelor in the EUCLID trial (15) conducted exclusively among symptomatic PAD patients, no significant differences between these two compounds could be demonstrated either regarding cardiovascular events or bleeding complications (15).

The protease-activated receptor 1 antagonist vorapaxar was found to reduce the risk of acute limb ischemia in the PAD subgroup in the $\mathrm{TRA}^{\circ} \mathrm{P}$-TIMI 50 study (41), but is also associated with increased risk for intracranial hemorrhage in patients with prior ischaemic cerebrovascular disease (34). In a meta-analysis of 49 RCTs comprising 34,518 patients neither aspirin, ticlopidine, ticagrelor, cilostazol, picotamide, or vorapaxar in monotherapy was superior to clopidogrel regarding the combined endpoint of efficacy and safety in PAD patients (16).

As no placebo arm was included in CAPRIE (14) and as EUCLID (15) lacked an aspirin arm, however, the evidence for platelet antiaggregation in PAD can still be somewhat disputed. Current guidelines $(3,4)$ recommend long-term single antiplatelet treatment with either aspirin or clopidogrel in symptomatic stable PAD patients who are not candidates for anticoagulant treatment as outlined below, provided they have no contra-indications such as increased bleeding risk, prior side effects of pharmacologic treatment, cognitive dysfunction, or other disabilities.

TABLE 1 | Summary of recommendations and concerns on antithrombotic treatment in peripheral arterial disease (PAD).

\begin{tabular}{|c|c|c|c|c|c|}
\hline & $\begin{array}{l}\text { Asymptomatic PAD } \\
\text { without other } \\
\text { symptomatic } \\
\text { atherosclerosis }\end{array}$ & $\begin{array}{l}\text { Stable } \\
\text { symptomatic } \\
\text { PAD }\end{array}$ & $\begin{array}{l}\text { After endovascular } \\
\text { intervention for PAD }\end{array}$ & $\begin{array}{l}\text { After open surgery for } \\
\text { PAD }\end{array}$ & $\begin{array}{l}\text { Peripheral ischemia } \\
\text { caused by cardioembolic } \\
\text { disease }\end{array}$ \\
\hline First line & No antithrombotic therapy & ASA or clopidogrel & ASA and low dose rivaroxaban & ASA or clopidogrel & DOAC \\
\hline Alternative & & $\begin{array}{l}\text { ASA and low dose } \\
\text { rivaroxaban }\end{array}$ & ASA and clopidogrel & $\begin{array}{l}\text { ASA and low dose } \\
\text { rivaroxaban }\end{array}$ & VKA \\
\hline References & $(3,4,11,12)$ & $(3,4,13-19)$ & $(3,4,20-23)$ & $(3,4,19,23-25)$ & $(3,4,26-33)$ \\
\hline
\end{tabular}

ASA, aspirin; DOAC, direct oral anticoagulant; VKA, vitamin K antagonist. 
TABLE 2 | Studies of antithrombotic therapy in peripheral arterial disease (PAD).

\begin{tabular}{|c|c|c|c|c|c|c|c|}
\hline $\begin{array}{l}\text { Study (first author } \\
\text { or eponym, year) }\end{array}$ & References & Patient population & Comparison & $\begin{array}{c}\text { Follow up } \\
\text { (mean or } \\
\text { median, months) }\end{array}$ & $\begin{array}{l}\text { Number of } \\
\text { patients }\end{array}$ & $\begin{array}{l}\text { RR or HR primary } \\
\text { outcome }(95 \% \mathrm{Cl})\end{array}$ & $\begin{array}{l}\text { RR or HR major } \\
\text { bleeding } \\
(95 \% \mathrm{Cl})\end{array}$ \\
\hline Fowkes et al., 2010 & $(11)$ & Asymptomatic PAD & Aspirin or placebo & 98 & 28,980 & $1.03(0.84-1.27)$ & $1.71(0.99-2.97)$ \\
\hline Belch et al., 2008 & $(12)$ & $\begin{array}{l}\text { Asymptomatic PAD } \\
\text { with diabetes }\end{array}$ & Aspirin or placebo & 80 & 1,276 & $0.98(0.76-1.26)$ & \\
\hline CAPRIE, 1996 & (14) & $\begin{array}{l}\text { Prior PAD, stroke, or } \\
\mathrm{Ml}\end{array}$ & Aspirin or clopidogrel & 23 & 19,185 & $\begin{array}{l}\text { Relative risk } \\
\text { reduction (\%) } 8.7 \\
(0.3-16.5)\end{array}$ & $\mathrm{NS}$ for $\mathrm{ICH}, p=0.23$ \\
\hline Hiatt et al., 2017 & (15) & Symptomatic PAD & Ticagrelor or clopidigrel & 30 & 13,885 & $1.02(0.92-1.13)$ & $1.10(0.84-1.43)$ \\
\hline Bonaca et al., 2016 & (34) & $\mathrm{PAD}$ and $\mathrm{Ml}$ & $\begin{array}{l}\text { Ticagrelor and aspirin or } \\
\text { aspirin only }\end{array}$ & 36 & 1,143 & $\begin{array}{l}\text { Absolute risk } \\
\text { reduction (\%) } 4.1 \\
(-1.07-9.29)\end{array}$ & $1.32(0.41-4.29)$ \\
\hline Bhatt et al., 2006 & (35) & $\begin{array}{l}\text { Cardiovascular } \\
\text { disease or multiple } \\
\text { risk factors }\end{array}$ & $\begin{array}{l}\text { Clopidogrel and aspirin or } \\
\text { aspirin only }\end{array}$ & 28 & 15,603 & $0.93(0.83-1.05)$ & $1.25(0.97-1.61)$ \\
\hline Anand et al., 2007 & (36) & PAD & $\begin{array}{l}\text { Aspirin and warfarin or } \\
\text { aspirin only }\end{array}$ & 35 & 2,161 & $0.92(0.73-1.16)$ & $3.41(1.84-6.35)$ \\
\hline Anand et al., 2018 & (18) & $\begin{array}{l}\text { Stable lower } \\
\text { exrtremity or carotid } \\
\text { PAD }\end{array}$ & $\begin{array}{l}\text { Low dose rivaroxaban and } \\
\text { aspirin or aspirin only }\end{array}$ & 21 & 7,470 & $0.72(0.57-0.90)$ & $1.61(1.12-2.31)$ \\
\hline $\begin{array}{l}\text { Tepe et al. 2012, } \\
\text { Strobel et al. } 2013\end{array}$ & $(21,22)$ & $\begin{array}{l}\text { After endovascular } \\
\text { PAD intervention }\end{array}$ & $\begin{array}{l}\text { Clopidogrel and aspirin or } \\
\text { aspirin only }\end{array}$ & 12 & 80 & $\begin{array}{l}\text { NS for } \\
\text { revascularization, } \\
p=0.35\end{array}$ & \\
\hline $\begin{array}{l}\text { Bonaca et al. } 2020 \text {, } \\
\text { Hiatt et al. } 2020\end{array}$ & $(23,37)$ & $\begin{array}{l}\text { After PAD } \\
\text { intervention }\end{array}$ & $\begin{array}{l}\text { Low dose rivaroxaban and } \\
\text { aspirin or aspirin only }\end{array}$ & 36 & 6,564 & $0.85(0.76-0.96)$ & $1.43(0.97-2.10)$ \\
\hline Dutch BOA, 2000 & (38) & $\begin{array}{l}\text { After open surgical } \\
\text { PAD intervention }\end{array}$ & $\begin{array}{l}\text { Oral anticoagulant or } \\
\text { aspirin }\end{array}$ & 21 & 2,690 & $0.95(0.82-1.11)$ & $1.96(1.42-2.71)$ \\
\hline Belch et al., 2010 & $(25)$ & $\begin{array}{l}\text { After open surgical } \\
\text { PAD intervention }\end{array}$ & $\begin{array}{l}\text { Aspirin and clopidogrel or } \\
\text { aspirin only }\end{array}$ & 12 & 851 & $0.98(0.78-1.23)$ & NS, 2.1 vs. $1.2 \%$ \\
\hline $\begin{array}{l}\text { Johnson et al., } \\
2002\end{array}$ & (39) & $\begin{array}{l}\text { After open surgical } \\
\text { PAD intervention }\end{array}$ & $\begin{array}{l}\text { Oral anticoagulant and } \\
\text { aspirin or aspirin only }\end{array}$ & Up to 60 & 831 & $\begin{array}{l}\text { NS for patency in } \\
\text { whole group }\end{array}$ & $\begin{array}{c}1.41(1.09-1.84) \text { for } \\
\text { death }\end{array}$ \\
\hline
\end{tabular}

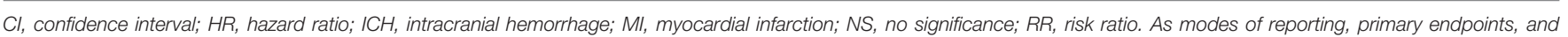
definitions of major bleeding differ in the different studies, please see the original publications for details.

\section{Dual Antiplatelet Therapy}

Dual antiplatelet therapy (DAPT) with a combination of 75$162 \mathrm{mg}$ of aspirin and $75 \mathrm{mg}$ of clopidogrel was evaluated in the CHARISMA trial (35) performed in 15,603 patients with either established vascular disease or multiple risk factors for atherosclerosis. Dual antiplatelet therapy compared to aspirin alone conferred no significant risk reduction (RR) for the primary study endpoint of either cardiovascular death, myocardial infarction, or stroke (RR 0.93; 95\% CI $0.83-1.05 ; p=0.22$ ), whereas a significant RR was demonstrated for the secondary endpoint; hospitalization for ischemia or revascularization (RR 0.92; 95\% CI 0.86-0.995; $p=0.04$ ). In the subgroup of 3,096 CHARISMA patients with PAD (17) of which the vast majority were symptomatic, however, both rates of myocardial infarction ( 2.3 vs. $3.7 \% ; p=0.029$ ), and hospitalization for ischemic events (16.5 vs. $20.1 \%$; $p=0.011$ ) were lower with DAPT than with aspirin alone. Rates of severe, fatal, or moderate bleeding did not differ, but minor bleeding occurred more often with DAPT (34.4 vs. $20.8 \% ; p=0.001$ ). As a subgroup analysis of a negative trial should not be used as a basis for treatment decisions, there is no guideline support for routine use of DAPT in patients with stable PAD $(3,4)$. This conclusion is also supported by results from the above mentioned meta-analysis of 49 RCTs comprising 34,518 patients (16).

\section{Combined Antiplatelet and Anticoagulant Therapy}

When the combination of antiplatelet treatment and full dose anticoagulation with warfarin was evaluated after myocardial infarction (42) it was found to be beneficial regarding risk for death, reinfarction or stroke, whereas no such benefits of combination therapy could be established when studying effects of the same combination in PAD patients in the WAVE trial (36). Furthermore, combination therapy also conferred unacceptable inceased bleeding rates in both study settings $(36,42)$.

When later evaluating the combination of aspirin with a direct oral anticoagulant (DOAC) in PAD patients, a lower dose of anticoagulation was therefore employed. The COMPASS study $(18,43)$ compared three different active treatments; a combination of low dose rivaroxaban $2.5 \mathrm{mg}$ twice daily and aspirin $100 \mathrm{mg}$ daily, rivaroxaban $5 \mathrm{mg}$ twice daily, and aspirin $100 \mathrm{mg}$ daily with corresponding placebos in 24,824 patients with 
stable coronary artery disease or PAD. In a subgroup analysis (18) of the 7,470 COMPASS patients with either stable lower extremity PAD or carotid artery disease, the combination of rivaroxaban $2.5 \mathrm{mg}$ twice daily and aspirin $100 \mathrm{mg}$ daily reduced both the primary composite endpoint cardiovascular death, myocardial infarction, or stroke (5 vs. $7 \% ; p=0.0047$ ), and the primary PAD-related endpoint "major adverse limb events" including amputation ( 1 vs. $2 \% ; p=0.0037$ ) compared to aspirin alone, whereas rivaroxaban $5 \mathrm{mg}$ twice daily did not confer any definitive benefits compared to aspirin (18). The combination of rivaroxaban and aspirin combination also increased major bleeding compared with aspirin alone (3 vs. $2 \%$; HR 1.61, $95 \%$ CI $1.12-2.31 ; p=0.0089)$, however, mainly due to an increased risk for gastrointestinal bleeding.

European PAD guidelines (4) issued after the publication of COMPASS $(18,43)$ therefore recommend that a combination of ASA $100 \mathrm{mg}$ daily and rivaroxaban $2.5 \mathrm{mg}$ twice daily should be considered in stable PAD patients without high bleeding risk or other relevant contraindications. The same consideration is also recommended in the global guidelines for treatment of patients with the most serious form of PAD, CTLI (19).

\section{ANTITHROMBOTIC TREATMENT AFTER INTERVENTION FOR PERIPHERAL ATHEROSCLEROTIC DISEASE}

\section{Endovascular Intervention}

Endovascular percutaneous transluminal angioplasty (PTA) with or without stent placement might increase the risk for thromboembolic events both by disrupting the endothelium or atherosclerotic plaques and by introduction of foreign material in the artery. This might activate platelets and coagulation factors, initiate atherothrombosis, and consequently increase the risk of arterial occlusion. In a systematic follow-up of nationwide Swedish registry data (44), the risk of non-fatal MI, ischemic stroke, or cardiovascular death 36 months after peripheral revascularization was $14 \%$ among patients with IC and and $34 \%$ among those with CLTI. Furthermore, the TRA ${ }^{\circ} \mathrm{P}$ study $(41,45)$ confirmed that peripheral revascularization increased the risk of acute limb ischemia and the need for both urgent and elective reintervention. Particular interest has therfore been focussed on this patient group when assessing effects of antithrombotic treatment.

Antiplatelet therapy after endovascular revascularization of peripheral arteries has often been based on recommendations (46) based on studies of patients undergoing percutaneous coronary interventions (PCI), and many vascular units routinely recommend a combination of aspirin and clopidogrel for 13 months after peripheral revascularization. One month of DAPT is also recommended in the current version of the PAD guidelines issued by the European Society of Vascular Surgery and European Society of Cardiology (3). A thourough meta-analysis (20) of 5,464 publications in the field in 2016 revealed, however, that only one of the evaluated articles was relevant. In the MIRROR trial $(21,22)$ the combination of aspirin and clopidogrel was compared with monotherapy with aspirin after percutaneous angioplasty with or without stenting in the femoropopliteal segment. The 6-month results of MIRROR (21) were promising with lower need for target lesion revascularization with combination therapy, but after 12 months of follow-up (22), this difference was no longer detectable.

Authors of the meta-analysis concluded that the lacking evidence for DAPT after lower limb endovascular revascularization might partly be explained by the fact that interventionalists have already adopted the DAPT regime used after PCI (46), making it difficult to conduct new randomized trials of DAPT after endovascular revascularization in PAD (20).

Furthermore, in the recently published VOYAGER study (23) rivaroxaban $2.5 \mathrm{mg}$ twice daily combined with aspirin $100 \mathrm{mg}$ daily was compared to aspirin $100 \mathrm{mg}$ and placebo in 6,564 patients revascularized due to symptomatic PAD. Revascularization had been performed with endovascular or hybrid methods in $65 \%$ of cases, and with open surgery in the remaining $35 \%$. The majority of patients were treated because of intermitent claudication, but $23 \%$ had CLTI. The combined primary efficacy endpoint of cardiovascular death, myocardial infarction, stroke, acute limb ischemia, or amputation above ankle occurred in $17.3 \%$ and $19.9 \%$ of patients in the combination and aspirin only group, respectively (HR 0.85 ; 95\% CI 0.76-0.96; $p=0.009$ ) during 36 months, corresponding to an absolute $\mathrm{RR}$ of $2.6 \%$ and a number needed to treat (NNT) of 39 . As the primary safety endpoint, major bleeding defined in accordance with the Thrombolysis In Myocardial Infarction (TIMI) classification (47), did not differ significantly between groups (2.7 and $1.9 \%$, $p=0.07)$, and as the safety of rivaroxaban was later shown to be consistent regardless of concomitant clopidogrel use (37), it must be concluded that the evidence is far more solid for the use of the combination of low doses of aspirin and rivaroxaban after endovascular peripheral revascularization than for DAPT.

\section{Open Vascular Surgery}

Full dose vitamin $\mathrm{K}$ antagonists was compared to aspirin in 2,690 patients having undergone infrainguinal bypass surgery in the Dutch Bypass Oral Anticoagulants or Aspirin (BOA) trial (38). The study was neutral (HR 0.95; 95\% CI 0.82-1.11), but subgroup analyses revealed that vitamin $\mathrm{K}$ antagonism conferred a reduction in graft occlusion (HR 0.69; 95\% CI 0.54-0.88) in patients receiving vein grafts, but an increased risk in those receiving prosthetic grafts (HR 1.26; 95\% CI 1.03-1.55). The evidence for vitamin $\mathrm{K}$ antagonist use after venous bypass has later been considered as insufficient in a Cochrane analysis (24), however.

The CASPAR study (25) showed no additive effect of combining aspirin with clopidogrel after open bypass surgery in lower limb arteries regarding the composite primary efficacy endpoint of index-graft occlusion, revascularization, above-ankle amputation of the affected limb, or death, except for in the subgroup of patients with prosthethic grafts. The combination of aspirin and full dose warfarin after lower extremity bypass was associated with both increased morbidity and mortality (39).

Guidelines $(3,4,19)$ therefore recommend single antiplatelet therapy after open surgery for PAD, although the different European guidelines mentions vitamin-K antagonists after 
venous bypass either as an alternative (4) or as an option for which evidence is weak and bleeding risk is higher compared to antiplatelet drugs (3) (Table 1).

As beneficial effects of combination therapy could be demonstrated also in the subgroup of VOYAGER patients having undergone revascularization with open surgical methods (23), however, the combination of low dose aspirin and rivaroxaban could well be considered also in this situation in patients without high bleeding risk or other contraindications.

\section{ANTICOAGULATION IN PATIENTS WITH PERIPHERIAL ISCHEMIA CAUSED BY CARDIAC EMBOLIZATION}

Cerebral embolism is by far the most common and feared embolic consequences of atrial fibrillation (AF), and $80 \%$ of deaths related to cardiogenic embolism are caused by ischemic stroke (48). Atrial fibrillation is also the most common cause of peripheral embolism, however, and estimated to be present in 60$95 \%$ of patients undergoing surgery for acute limb ischemia (49). The yearly incidence of aortoiliac and lower-extremity arterial thromboembolism in AF is about 0.4\%, corresponding to an excess risk of 4.0 (95\% CI 3.5-4.6) in men and 5.7 (95\% CI 5.1-6.3) in women (50).

Current European guidelines for AF (26) recommend assessment of the risk for systemic cardiac embolisation by evaluation of the factors below summarized in the $\mathrm{CHA}_{2} \mathrm{DS}_{2}$ VASc score (50). As anticoagulant treatment is recommended already in patients with $\mathrm{CHA}_{2} \mathrm{DS}_{2}$-VASc score $\geq 1$ in men and $\geq 2$ in women (26), and as a previous episode of thromboembolism (S) confers two points, all patients with permanent or paroxysmal AF who have suffered an episode of lower extremity embolism have a score of 2 or higher. After endovascular, open surgical, or thrombolytic treatment of the acute event, they should therefore be offered secondary prevention by full dose anticoagulation in the abscence of important contraindications. This recommendation also applies to patients with peripheral embolization caused by prosthethic heart valves or other cardiac sources of embolism (3).

As the presence of atherosclerotic peripheral vascular disease in itself confers one $\mathrm{CHA}_{2} \mathrm{DS}_{2}$-VASc point (26), most PAD patients with concomitant AF will qualify for anticoagulation also in the abscence of documented thromboembolic episodes in the lower extremities.

In patients with an established indication for anticoagulation undergoing endovascular PAD recanalization, European guidelines recommend consideration of a 1-12 month course of aspirin or clopidogrel as addition to the anticoagulant in the abscence of high bleeding risk $(3,4)$. After open surgical procedures for PAD in this patient group, on the other hand, only continued anticoagulation is recommended $(3,4)$.

Direct oral anticoagulant, the thrombin inhibitor dabigatran (27) or one of the factor Xa-inhibitors rivaroxaban (28), edoxaban (29), and apixaban (30) are first hand alternatives for anticoagulation. Meta-analysis (31) has established that treatment with these agents in comparison to warfarin confers $19 \%$ RR for stroke or other systemic embolism and a 51\% $\mathrm{RR}$ in haemorrhagic stroke. Direct oral anticoagulant treatment was also associated with a non-significant $14 \%$ reduction in major bleeding risk, a 52\% reduction in intracranial hemorrhage, and a $25 \%$ increase in gastrointestinal bleeding compared to warfarin (31). Although focus in the above trials (2730) and meta-analysis (31) has been on stroke prevention with DOAC, a systematic literature review (32) confirmed that DOAC are also at least as effective as warfarin to reduce the risk for limb ischemia in patients with AF. Furthermore, among patients with AF and concomitant CLTI, the superiority of DOAC in comparison to either warfarin or antiplatelet therapy has been established in a retrospective cohort analysis (33).

Warfarin can of course still be used as an alternative for prevention of systemic thromboembolic events in patients with $\mathrm{AF}$ or other sources of embolism to peripheral arteries (26), however, and is superior to dabigatran in patients with mechanical heart valves (51) and to rivaroxaban in those with antiphospholipid syndrome (52). The therapeutic target is an international normalized ratio (INR) of 2.0-3.0. There is no evidence for warfarin treatment with lower INR-targets, or for combination treatment with warfarin in combination with aspirin or other antiplatelet agents in PAD.

\section{EMERGING ROLE, UNMET NEEDS, AND GRAY AREAS}

The benefits of combined treatment with low doses of aspirin and rivaroxaban has been established in both stable PAD $(18,43)$ and after peripheral revascularization $(23,37)$, and this benefit increases with baseline risk in the patient (53). Bleeding risk with this treatment also has to be taken into account, however, and PAD patients with a perceived high risk for bleeding complications were excluded from the studies. We must therefore more clearly define the groups of PAD patients in which combination treatment with low doses of aspirin and rivaroxaban is safe and cost-effective in clinical practice.

Furthermore, we lack studies establishing the efficacy and safety of combined antitplatelet and full dose anticoagulant treatment after peripheral revascularization in patients with $\mathrm{AF}$ or other established indications for anticoagulation. To which patients in this group should platelet inhibition be added to the oral anticoagulation, and for how long after the intervention?

Neither do we know if PAD progression in itself, measured for example as a worsening $\mathrm{ABI}$, is enough to warrant modification of antithrombotic therapy.

\section{SUMMARY}

Whereas asymptomatic PAD does not warrant either anticoagulant or antiplatelet treatment, patients with ischaemic symptoms such as intermittent claudication or CLTI caused 
by atherosclerosis should be offered platelet antiaggregation with either low dose aspirin or clopidogrel, and those with cardioembolic disease should be recommended full dose anticoagulant treatment with either DOAC or warfarin. Combined treatment with aspirin and low dose rivaroxaban should be considered and weighed against bleeding risk in symptomatic PAD patients with high risk for recurrent ischaemic events and in those having undergone peripheral endovascular or open surgical intervention. These concerns and recommendations are summarized in Table $\mathbf{1}$.

\section{REFERENCES}

1. Fowkes FG, Rudan D, Rudan I, Aboyans V, Denenberg JO, McDermott MM, et al. Comparison of global estimates of prevalence and risk factors for peripheral artery disease in 2000 and 2010: a systematic review and analysis. Lancet. (2013) 382:1329-40. doi: 10.1016/S0140-6736(13)61249-0

2. Criqui MH, Aboyans V. Epidemiology of peripheral artery disease. Circ Res. (2015) 116:1509-26. doi: 10.1161/CIRCRESAHA.116.303849

3. Aboyans V, Ricco JB, Bartelink MEL, Björck M, Brodmann M, Cohnert T, et al. 2017 ESC guidelines on the diagnosis and treatment of peripheral arterial diseases, in collaboration with the European Society for Vascular Surgery (ESVS). Eur J Vasc Endovasc Surg. (2018) 55:305-68. doi: 10.1016/j.ejvs.2017.07.018

4. Frank U, Nikol S, Belch J, Boc V, Brodmann M, Carpentier PH, et al. European Society of Vascular Medicine (ESVM) guideline on peripheral arterial disease. Vasa. (2019) 48(Suppl 102):1-79. doi: 10.1024/0301-1526/a000834

5. Steg PG, Bhatt DL, Wilson PWF. D’Agostino Sr R, Ohman EM, Röther J, et al. One-year cardiovascular event rates in outpatients with atherothrombosis. $J$ Am Med Assoc. (2007) 297:1197-206. doi: 10.1001/jama.297.11.1197

6. Heald CL, Fowkes FGR, Murray GD, Price JF, Ankle Brachial Index Collaboration. Risk of mortality and cardiovascular disease associated with the ankle-brachial index: systematic review. Atherosclerosis. (2006) 189:61-9. doi: 10.1016/j.atherosclerosis.2006.03.011

7. Criqui MH, Ninomiya JK, Wingard DL Ji M, Fronek A. Progression of peripheral arterial disease predicts cardiovascular disease morbidity and mortality. J Am Coll Cardiol. (2008) 52:1736-42. doi: 10.1016/j.jacc.2008.07.060

8. Bullen C. Impact of tobacco smoking and smoking cessation on cardiovascular risk and disease. Expert Rev Cardiovasc Ther. (2008) 6:883-95. doi: 10.1586/14779072.6.6.883

9. Mach F, Baigent C, Catapano AL, Koskinas KC, Casula M, Badimon L, et al. 2019 ESC/EAS Guidelines for the management of dyslipidaemias: lipid modification to reduce cardiovascular risk: the Task Force for the management of dyslipidaemias of the European Society of Cardiology (ESC) and European Atherosclerosis Society (EAS). Eur Heart J. (2019) 41:111-88. doi: 10.1093/eurheartj/ehz455

10. Williams B, Mancia G, Spiering W, Agabiti Rosei E, Azizi M, Burnier M, et al. 2018 ESC/ESH guidelines for the management of arterial hypertension. Eur Heart J. (2018) 39:3021-104. doi: 10.1093/eurheartj/ehy339

11. Fowkes FG, Price JF, Stewart MC, Butcher I, Leng GC, Pell AC, et al. Aspirin for prevention of cardiovascular events in a general population screened for a low ankle brachial index: a randomized controlled trial. JAMA. (2010) 303:841-8. doi: 10.1001/jama.2010.221

12. Belch J, MacCuish A, Campbell I, Cobbe S, Taylor R, Prescott R, et al. The prevention of progression of arterial disease and diabetes (POPADAD) trial: factorial randomised placebo controlled trial of aspirin and antioxidants in patients with diabetes and asymptomatic peripheral arterial disease. $B M J$. (2008) 337:a1840. doi: 10.1136/bmj.a1840

13. Antithrombotic Trialists' Collaboration. Collaborative meta-analysis of randomised trials of antiplatelet therapy for prevention of death, myocardial infarction, and stroke in high risk patients. BMJ. (2002) 324:71-86. doi: $10.1136 /$ bmj.324.7329.71

\section{AUTHOR'S NOTE}

AG is the only author of this review submitted for the research topic-Anticoagulation in cardiovascular diseases: evolving role, unmet needs, and gray areas.

\section{AUTHOR CONTRIBUTIONS}

The author confirms being the sole contributor of this work and has approved it for publication.

14. CAPRIE Steering Committee. A randomised, blinded, trial of clopidogrel versus aspirin in patients at risk of ischaemic events (CAPRIE). Lancet. (1996) 348:1329-39. doi: 10.1016/s0140-6736(96)09457-3

15. Hiatt WR, Fowkes FGR, Heizer G, Berger JS, Baumgartner I, Held P, et al. Ticagrelor versus clopidogrel in symptomatic peripheral artery disease. $\mathrm{NEngl}$ J Med. (2017) 376:32-40. doi: 10.1056/NEJMoa1611688

16. Katsanos K, Spiliopoulos S, Saha P, Diamantopoulos A, Karunanithy $\mathrm{N}$, Krokidis $\mathrm{M}$, et al. Comparative efficacy and safety of different antiplatelet agents for prevention of major cardiovascular events and leg amputations in patients with peripheral arterial disease: a systematic review and network meta-analysis. PLoS ONE. (2015) 10:e0135692. doi: 10.1371/journal.pone.0135692

17. Cacoub PP, Bhatt DP, Steg PG, Topol EJ, Creager MA. Patients with peripheral arterial disease in the CHARISMA trial. Eur Heart J. (2009) 30:192-201. doi: 10.1093/eurheartj/ehn534

18. Anand SS, Bosch J, Eikelboom JW, Connolly SJ, Diaz R, Widimsky $\mathrm{P}$, et al. Rivaroxaban with or without aspirin in patients with stable peripheral or carotid artery disease: an international, randomised, double-blind, placebo-controlled trial. Lancet. (2018) 391:219-29. doi: 10.1016/S0140-6736(17)32409-1

19. Conte MS, Bradbury AW, Kolh P, White JV, Dick F, Fitridge R, et al. Global vascular guidelines on the management of chronic limbthreatening ischemia. Eur J Vasc Endovasc Surg. (2019) 58:S1.e33-109.e33. doi: 10.1016/j.ejvs.2019.05.006

20. Peeters Weem SMO, van Haelst STW, den Ruijter HM, Moll FL, de Borst GJ. Lack of evidence for dual antiplatelet therapy after endovascular arterial procedures: a meta-analysis. Eur J Vasc Endovasc Surg. (2016) 52:253-62. doi: 10.1016/j.ejvs.2016.04.023

21. Tepe G, Bantleon R, Brechtel K, Schmehl J, Zeller T, Claussen CD, et al. Management of peripheral arterial interventions with mono or dual antiplatelet therapy-the MIRROR study: a randomised and double blinded clinical trial. Eur Radiol. (2012) 22:1998-2006. doi: 10.1007/s00330-012-2441-2

22. Strobl FF, Brechtel K, Schmehl J, Zeller T, Reiser MF, Claussen CD, et al. Twelve-month results of a randomized trial comparing mono with dual antiplatelet therapy in endovascularly treated patients with peripheral artery disease. J Endovasc Ther. (2013) 20:699-706. doi: 10.1583/13-4275MR.1

23. Bonaca MP, Bauersachs RM, Anand SS, Debus ES, Nehler MR, Patel MR, et al. Rivaroxaban in peripheral artery disease after revascularization. N Engl J Med. (2020) 382:1994-2000. doi: 10.1056/NEJMoa2000052

24. Geraghty AJ, Welch K. Antithrombotic agents for preventing thrombosis after infrainguinal arterial bypass surgery. Cochrane Database Syst Rev. (2011) 6:CD000536. doi: 10.1002/14651858.CD000536.pub2

25. Belch JJ, Dormandy J, Biasi GM, Cairols M, Diehm C, Eikelboom B, et al. Results of the randomized, placebo-controlled clopidogrel and acetylsalicylic acid in bypass surgery for peripheral arterial disease. J Vasc Surg. (2010) 52:825-33. doi: 10.1016/j.jvs.2010.04.027

26. Hindricks G, Potpara T, Dagres N, Arbelo E, Bax JJ, Blomström-Lundqvist C, et al. 2020 ESC Guidelines for the diagnosis and management of atrial fibrillation developed in collaboration with the European Association for Cardio-Thoracic Surgery (EACTS): the Task Force for the diagnosis and management of atrial fibrillation of the European Society of Cardiology 
(ESC) Developed with the special contribution of the European Heart Rhythm Association (EHRA) of the ESC. Eur Heart J. (2021) 42:373-498. doi: 10.1093/eurhearti/ehaa612

27. Connolly SJ, Ezekowitz MD, Yusuf S, Eikelboom J, Oldgren J, Parekh A, et al. Dabigatran versus warfarin in patients with atrial fibrillation. $N$ Engl J Med. (2009) 361:1139-51. doi: 10.1056/NEJMoa0905561

28. Patel MR, Mahaffey KW, Garg J, Guohua Pan G, Daniel E. Singer DE, Werner Hacke W, et al. Rivaroxaban vswarfarin in nonvalvular atrial fibrillation. $N$ Engl J Med. (2011) 365:883-91. doi: 10.1056/NEJMoa1009638

29. Geller BJ, Giugliano RP, Braunwald E, Murphy SA, Hanyok JJ, Jin J, et al. Systemic, noncerebral, arterial embolism in 21,105 patients with atrial fibrillation randomized to edoxaban or warfarin: results from the effective anticoagulation with factor Xa next generation in atrial fibrillationthrombolysis in myocardial infarction study 48 trial. Am Heart J. (2015) 170:669-74. doi: 10.1016/j.ahj.2015.06.020

30. Granger CB, Alexander JH, McMurray JJ, Lopes RD, Hylek EM, Hanna M, et al. Apixaban versus warfarin in patients with atrial fibrillation. N Engl J Med. (2011) 365:981-92. doi: 10.1056/NEJMoa1107039

31. Ruff CT, Giugliano RP, Braunwald E, Hoffman EB, Deenadayalu N, Ezekowitz $\mathrm{MD}$, et al. Comparison of the efficacy and safety of new oral anticoagulants with warfarin in patients with atrial fibrillation: a meta-analysis of randomised trials. Lancet. (2014) 383:955-62. doi: 10.1016/S0140-6736(13)62343-0

32. De Haro J, Bleda S, Varela C, Cañibano C, Acin F. Meta-analysis and adjusted indirect comparison of direct oral anticoagulants in prevention of acute limb ischemia in patients with atrial fibrillation. Curr Med Res Opin. (2016) 32:1167-73. doi: 10.1185/03007995.2016.1163256

33. Lee HF, Chan YH Li PR, Liu JR, Chao TF, Wu LS, et al. Oral anticoagulants and antiplatelet agents in patients with atrial fibrillation and concomitant critical limb ischemia: a nationwide cohort study. Can J Cardiol. (2021) 37:113-21. doi: 10.1016/j.cjca.2020.02.071

34. Bonaca MP, Bhatt DL, Storey RF, Steg PG, Cohen M, Kuder J, et al. Ticagrelor for prevention of ischemic events after myocardial infarction in patients with peripheral artery disease. J Am Coll Cardiol. (2016) 67:2719-28. doi: 10.1016/j.jacc.2016.03.524

35. Bhatt DL, Fox KA, Hacke W, Berger PB, Black HR, Boden WE, et al. Clopidogrel and aspirin versus aspirin alone for the prevention of atherothrombotic events. N Engl J Med. (2006) 354:1706-17. doi: 10.1056/NEJMoa060989

36. Warfarin Antiplatelet Vascular Evaluation Trial Investigators, Anand SYS, Yusuf S, Xie C, Pogue J, Eikelboom J, et al. Oral anticoagulant and antiplatelet therapy and peripheral arterial disease. N Engl J Med. (2007) 357:217-27. doi: 10.1056/NEJMoa065959

37. Hiatt WR, Bonaca MP, Patel MR, Nehler MR, Debus ES, Anand SS, et al. Rivaroxaban and aspirin in peripheral artery disease lower extremity revascularization. Impact of concomitant clopidogrel on efficacy and safety. Circulation. (2020) 142:2219-30. doi: 10.1161/CIRCULATIONAHA.120.050465

38. Efficacy of oral anticoagulants compared with aspirin after infrainguinal bypass surgery (The Dutch Bypass Oral Anticoagulants or Aspirin Study): a randomised trial. Lancet. (2000) 355:346-51.

39. Johnson WC, Williford WO. Benefits, morbidity, and mortality associated with long-term administration of oral anticoagulant therapy to patients with peripheral arterial bypass procedures: a prospective randomized study. J Vasc Surg. (2002) 35:413-21. doi: 10.1067/mva.2002.12184

40. Janzon L, Bergqvist D, Boberg J, Boberg M, Eriksson I, Lindgärde F, et al. Prevention of myocardial infarction and stroke in patients with intermittent claudication; effects of ticlopidine. Results from STIMS, the Swedish Ticlopidine Multicentre Study. J Intern Med. (1990) 227:301-8. doi: 10.1111/j.1365-2796.1990.tb00164.x

41. Bonaca MP, Gutierrez JA, Creager MA, Scirica BM, Olin J, Murphy $\mathrm{SA}$, et al. Acute limb ischemia and outcomes with vorapaxar in patients with peripheral artery disease: results from the trial to assess the effects of vorapaxar in preventing heart attack and stroke in patients with atherosclerosis-thrombolysis in myocardial infarction 50 (TRA2 ${ }^{\circ}$ P-TIMI $\quad$ 50). Circulation. (2016) 133:997-1005. doi: 10.1161/CIRCULATIONAHA.115.019355

42. Hurlen M, Abdelnoor M, Smith P, Erikssen J, Arnesen H. Warfarin, aspirin, or both after myocardial infarction. N Engl J Med. (2002) 347:969-74. doi: 10.1056/NEJMoa020496

43. Eikelboom JW, Connolly SJ, Bosch J, Dagenais GR, Hart RG, Shestakovska O, et al. Rivaroxaban with or without aspirin in stable cardiovascular disease. $N$ Engl J Med. (2017) 377:1319-30. doi: 10.1056/NEJMoa1709118

44. Sigvant B, Kragsterman B, Falkenberg M, Hasvold P, Johansson S, Thuresson $\mathrm{M}$, et al. Contemporary cardiovascular risk and secondary preventive drug treatment patterns in peripheral artery disease patients undergoing revascularization. J Vasc Surg. (2016) 64:1009.e3-17.e3. doi: 10.1016/j.jvs.2016.03.429

45. Bonaca MP, Creager MA, Olin J, Scirica BM, Gilchrist IC, Murphy SA, et al. Peripheral revascularization in patients with peripheral artery disease with vorapaxar: insights from the TRA $2{ }^{\circ} \mathrm{P}$-TIMI 50 trial. JACC Cardiovasc Interv. (2016) 9:2157-64. doi: 10.1016/j.jcin.2016.07.034

46. Windecker S, Kolh P, Alfonso F, Collet JP, Cremer J, Falk V, et al. 2014 ESC/EACTS guidelines on myocardial revascularization: the task force on myocardial revascularization of the European Society of Cardiology (ESC) and the European Association for Cardio-Thoracic Surgery (EACTS). Eur Heart J. (2014) 35:2541-619. doi: 10.1093/eurheartj/ehu278

47. Wiviott SD, Braunwald E, McCabe CH, Montalescot G, Ruzyllo W, Gottlieb S, et al. Prasugrel versus clopidogrel in patients with acute coronary syndromes. N Engl J Med. (2007) 357:2001-15. doi: 10.1056/NEJMoa0706482

48. Menke J, Lüthje L, Kastrup A, Larsen J. Thromboembolism in atrial fibrillation. Am J Cardiol. (2010) 105:502-10. doi: 10.1016/j.amjcard.2009.10.018

49. Wasilewska M, Gosk-Bierska I. Thromboembolism associated with atrial fibrillation as a cause of limb and organ ischemia. Adv Clin Exp Med. (2013) 22:e73.

50. Frost L, Engholm G, Johnsen S, Moller H, Henneberg EW, Husted S. Incident thromboembolism in the aorta and the renal, mesenteric, pelvic, and extremity arteries after discharge from the hospital with a diagnosis of atrial fibrillation. Arch Intern Med. (2001) 161:272-6. doi: 10.1001/archinte.161.2.272

51. Eikelboom JW, Connolly SJ, Brueckmann M, Granger CB, Kappetein AP, Mack MJ, et al. Dabigatran versus warfarin in patients with mechanical heart valves. N Engl J Med. (2013) 369:1206-14. doi: 10.1056/NEJMoa1300615

52. Pengo V, Denas G, Zoppellaro G, Jose SP, Hoxha A, Ruffatti A, et al. Rivaroxaban vs warfarin in high-risk patients with antiphospholipid syndrome. Blood. (2018) 132:1365-71. doi: 10.1182/blood-2018-04-848333

53. Eikelboom JW, Bhatt DL, Fox KAA, Bosch J, Connolly SJ, Anand SS, et al. Mortality benefit of rivaroxaban plus aspirin in patients with chronic coronary or peripheral artery disease J Am Coll Cardiol. (2021) 78:14-23. doi: 10.1016/J.JACC.2021.04.083

Conflict of Interest: The author declares that the research was conducted in the absence of any commercial or financial relationships that could be construed as a potential conflict of interest.

Publisher's Note: All claims expressed in this article are solely those of the authors and do not necessarily represent those of their affiliated organizations, or those of the publisher, the editors and the reviewers. Any product that may be evaluated in this article, or claim that may be made by its manufacturer, is not guaranteed or endorsed by the publisher.

Copyright $\odot 2021$ Gottsäter. This is an open-access article distributed under the terms of the Creative Commons Attribution License (CC BY). The use, distribution or reproduction in other forums is permitted, provided the original author(s) and the copyright owner(s) are credited and that the original publication in this journal is cited, in accordance with accepted academic practice. No use, distribution or reproduction is permitted which does not comply with these terms. 